JOPE

JOURNAL OF SPORT EDUCATION

Volume 1, Nomor 2, 2019: 49-55

P-ISSN : 2654-4474

E-ISSN : 2654-9069

\title{
Hubungan Koordinasi Mata Kaki Terhadap Keterampilan Sepak Sila Permainan Sepak Takraw
}

\author{
Rifki Nanda Putra ${ }^{1}$, uuaddi $^{2}$ \\ Universitas Islam Riau ${ }^{1}$, Universitas Negeri Yogyakarta ${ }^{2}$ \\ rifkinp25@gmail.com ${ }^{1}$, anwar92fuaddi.af@ gmail.com²
}

\begin{abstract}
Abstrak
Rendahnya kemampuan sepak sila siswa putra SMP N 5 Kota Pekanbaru karenakurangnya Koordinasi mata terhadap gerakan kaki saat melakukan sepak sila. tujuan dalam penelitian ini adalah untuk mengetahui Hubungan kooordinasi mata kaki terhadap keterampilan sepak sila permainan sepak takraw siswa putra kelas VIII SMP N 5 Kota. Jenis penelitian ini adalah penelitian korelasional dengan metode yang digunakan adalah metode eksperiment dengan uji korelasi Penelitian ini dilakukan di SMP N 5 Kota Pekanbaru dengan populasi siswa putra kelas VIII yang berjumlah 12 orang. Karena jumlah populasi sedikit, yakni kurang dari 100 orang maka seluruh populasi dijadikan sebagai sampel penelitian yang disebut juga total sampling. Teknik pengolahan data dengan menggunakan 2 tes, tes koordinasi mata kaki dan tes sepak sila, selanjutnya teknik analisa data yang diperoleh diuji signifikasinya dengan uji t.Berdasarkan analisa data diperoleh $\mathrm{t}_{\text {hitung }}=24,88>\mathrm{t}_{\text {tabel }}=2,23$. Hasil penelitian ini adalah signifikan, maka dapat disimpulkan bahwa terdapat HubunganKoordinasi Mata Kaki Terhadap Keterampilan Sepak sila Permainan Sepak takraw Siswa Putra Kelas VIII SMP N 5 Kota Pekanbaru, dengan demikian Ha diterima.
\end{abstract}

\begin{abstract}
The Low ability of kick sila of boy student SMPN 5 Kota Pekanbaru is due to lack of eyes coordination to the movement of the foot during a kick sila. The purpose of this study was to determine the correlation between ankles coordination towards the kick sila skill sepak takraw boy students VIII grade at SMP N 5 Kota Pekanbaru. This type of research is co-relational research and the method used in this study is the the experimental method with a correlation test. This research conducted at SMPN 5 Kota Pekanbaru which boy students VIII grade population amount 12 students. Because the population was small, which are less than 100 people, the entire population is used as a sample study also called total sampling. Data processing techniques by using the 2 tests, coordination ankle test and kick sila (sepak sila), furthermore data analysis technique was tested significance by $t$-test. Based on analysis of the data obtained $t=24.88>$ table $=2,23$. Results of this study are significant, it can be concluded that there is a correlation or relationship between Ankles Coordination towards Kick Sila (sepak sila) in Sepak Takraw Boy Student's Game VIII grade at SMP N 5 Kota Pekanbaru, thereby Ha accepted.
\end{abstract}




\section{PENDAHULUAN}

Dalam dunia pendidikan keterampilan olahraga diajarkan pada mata pelajaran yang bernama pendidikan jasmani dan kesehatan yang sering disingkat penjaskes. Pada mata pelajaran ini, siswa diajarkan gerak-gerak fundamental yang mendukung aktifitas olahraga. Selain itu sebagai upaya untuk menanamkan nilai-nilai moral dan jiwa sportif sejak dini kepada generasi muda yang nantinya diharapkan sebagai regenerasi atlit yang mewakili bangsa.

Pendidikan jasmani merupakan bagian integral dari pendidikan keseluruhan dan sebagai penunjang tercapainya pendidikan nasional (Herliana, 2017). Dengan diberikannya pendidikan jasmani di sekolah dengan memperhatikan nilai-nilai dalam pertumbuhan, perkembangan dan tingkah laku manusia, maka diharapkan siswa akan dapat tumbuh dan berkembang secara optimal.

Sekolah dipandang sebagai lembaga yang memiliki otoritas, dimana para siswa berpartisipasi pasif didalam program yang direncanakan, tetapi pada saat ini keadaan sekolah dan para siswa telah berubah. Perubahan yang makin meningkat mengakui bahwa hak-hak siswa individual harus dilindungi, dan kebutuhan pendidikan mereka harus dipenuhi. Oleh karena itu, apabila sesuatu sekolah ingin berhasil maka partisipasi aktif para siswa dalam berbagai keputusan harus ditingkatkan. Langkah tepat harus diambil kepala sekolah untuk mengembangkan pengertian yang lebih besar dan memahami isi hati para siswa.

Berdasarkan pemahaman tersebut, bahwa kegiatan olahraga perlu ditingkatkan dan disebarluaskan mulai dari kota sampai ke pelosok desa agar masyarakat dapat terbina fisik dan mempunyai mental yang baik. Maka untuk kelanjutannya perlu ditingkatkan lagi ke arah yang lebih baik menuju ke olahraga prestasi seperti yang terdapat dalam Undang-Undang Olahraga No.3 Tahun 2005 pasal 27 ayat menyebutkan: "Pembinaan dan pengembangan keolahragaan nasional yang dapat menjamin pemerataan akses terhadap olahraga, peningkatan kesehatan dan kebugaran, peningkatan prestasi, dan manajemen keolahragaan yang mampu menghadapi tantangan serta tuntutan perubahan kehidupan nasional dan global memerlukan sistem keolahragaan nasiona" (Undang-Undang Olahraga No.3 Tahun 2005 dalam Gazali, 2016))

Masuknya sepaktakraw sebagai materi pilihan ini merupakan dampak yang begitu luas. Cara bermainnya yang cukup atraktif membuat olahraga ini cukup disukai anak-anak. Dipelajari dan mulai dimainkan di sekolah, dan pada akhirnya di tempat tinggal mereka, dalam bentuk perkumpulan (club) sepaktakraw.

Dalam konteks pendidikan, sepaktakraw merupakan salah satu materi pilihan yang disajikan dalam bentuk kurikulum pendidikan jasmani di sekolah, sehingga sepaktakraw dapat digunakan sebagai media sarana dalam pembelajaran pendidikan jasmani di sekolah tersebut. Dengan aktifitas fisik melalui sepaktakraw tersebut, diharapkan akan mampu mengembangkan kemampuan organik, neuro-meskuler dalam bidang olahraga sepaktakraw sangat antusias pada olahraga tersebut.

Sepak takraw adalah suatu bentuk permainan yang dimainkan oleh dua regu/ tim yang masing-masing tim terdiri dari tiga pemain (Suhardi, Triansyah, \& Haetami, 2012). Bentuk olahraga ini adalah pertandingan dimana sisi lawan saling berhadapan dibatasi oleh sebuah net atau jaring yang dipimpin permainannya oleh seorang wasit dibantu asisten wasit (Sukmana \& Allsabah, 2018).

Adapun untuk bisa bermain sepaktakraw dengan baik seorang pemain harus menguasai teknik dasarnya terlebih dahulu. Salah satu teknik dasar yang paling utama adalah sepak sila (Setiawan, Yunitaningrum, \& Atiq, 2014). Sepak sila 
adalah menyepak dengan menggunakan kaki bagian dalam (Sulaiman, 2004).

Dalam permainan sepaktakraw teknik dasar sepak sila harus benar-benar dikuasai dengan baik, agar dalam bermain bisa optimal. Sepak sila sangat berpengaruh terhadap kualitas bermain, karena dengan sepak sila sangat mudah melancarkan serangan-serangan/memberi umpan kepada teman untuk dismash (Kurniawan dalam Setiawan et al., 2014).

Untuk mampu menguasai kemampuan sepak sila dengan baik, juga harus memiliki kemampuan motorik yang baik. Kemampuan motorik merupakan salah satu indikator kebugaran yang penting pada setiap individu yang erat kaitannya dengan pencapaian kualitas fisik dan kualitas keterampilan gerak, atau dapat pula didefenisikan bahwa kemampuan motorik adalah kapasitas penampilan seseorang dalam melakukan berbagai tugas gerak (Widiastuti, 2011). Hal ini sesuai dengan pendapat Suhartini dalam (Cendra, Gazali, Parulian, Candra, \& Apriani, 2018) perkembangan motorik sangat berkaitan erat dengan kegiatan fisik. Dalam hal ini, kemampuan motorik yang dimaksud adalah koordinasi gerakan yaitu koordinasi gerak antara mata-kaki.

Koordinasi mata, dan kaki adalah kemampuan dalam mengkoordinasikan mata, dan kaki dalam sebuah rangkaian gerak yang utuh, menyeluruh, serta terus menerus secara cepat dan tepat dalam irama gerak yang terkontrol (Anggraini, 2016).

Melihat dari bentuk gerakan permainan sepak takraw yang cukup atraktif, koordinasi menjadi aspek kondisi fisik yang cukup menentukan keberhasilan dalam permainan sepak takraw (Ucup, 2004). Selain itu, menurut (Anggraini, 2016) olahraga sepak takraw sangat membutuhkan koordinasi mata dan kaki, hal ini sangat berpengaruh dalam melakukan passing dan beberapa gerakan lainnya.
Berdasarkan hasil observasi yang penulis lakukan dalam pelaksanaan olahraga sepaktakraw yang dilaksanakan di SMP Negeri 5 Kota Pekanbaru, perkenaan bola pada mata kaki yang belum tepat Hal ini juga ternyata dilatar belakangi oleh faktor kurangnya kordinasi mata terhadap gerakan kaki siswa pada saat melakukan passing dalam bermain sepaktakraw di SMP Negeri 5 Kota Pekanbaru, gerakan siswa terlihat kaku sehingga bola tidak dapat dikontrol dengan baik, dan kekuatan passing kadang-kadang kuat sehingga bola tidak dapat memasuki kotak lawan dengan baik atau bola keluar, disamping itu kurangnya sarana dan prasarana sepaktakraw. Jadi saya harap yang akan saya teliti dalam penelitian ini bisa membangkitkan latihan yang saya ingin kan dari koordinasi mata kaki terhadap keterampilan sepak sila permainan sepak takraw.

Penelitian serupa sudah pernah dilakukan oleh peneliti lain sebelumnya, sebagai contoh (Nusufi, 2014) dan (Saripin \& Agust, 2017) mengatakan terdapat hubungan yang cukup kuat antara sampai pada hubungan yang siknifikan antara koordinasi mata kaki dengan kemampuan sepak sila. Penelitian yang peneliti lakukan ini merupakan peneltian yang bertujuan sebagai penguat dari pendapat-pendapat sebelumnya yang mengatakan bahwa koordinasi mata kaki memiliki kontribusi yang siknifikan terhadap kemampuan sepak sila.

\section{METODE PENELITIAN}

Metode penelitian yang digunakan adalah metode korelasional. Metode korelasional adalah metode yang digunakan untuk mencari hubungan antara dua variabel yang berbeda (Sugiyono, 2013). Variabel adalah hal yang menjadi pokok penelitian dalam hal ini terdiri dari variabel $\mathrm{x}$ dan $\mathrm{y}$. Variabel $\mathrm{x}$ atau variabel bebas adalah koordinasi mata kaki dan y atau variabel terikat adalah keterampilan passing sepak sila. 
Untuk mempermudah mengetahui langkah-langkah yang dilakukan pada proses penelitian, maka diperlukan design penelitian. Agar penelitian yang dilakukan tidak keluar dari ketentuan yang telah ditetapkan.

Dalam penelitian ini populasinya adalah siswa putra kelas XI SMP Negeri 5 Kota Pekanbaru adalah berjumlah 18 orang siswa putra. Mengingat jumlah populasi yang peneliti gunakan dalam penelitian ini tidak begitu banyak serta masih dalam batas kemampuan peneliti, maka teknik penelitian yang digunakan peneliti adalah menggunakan teknik sampel jenuh untuk mengambil sampel, dan seluruh populasi diatas dijadikan sampel penelitian.Dengan demikian jmlah sampel dalam penelitian ini sebanyak 18 orang siswa putra SMP Negeri 5 Kota Pekanbaru.

Teknik pengumpulan data dalam penelitian ini dengan menggunakan metode sebagai berikut:

1. Observasi, yakni melakukan pengamatan langsung ke lapangan untuk mendapatkan informasi atau data yang akan dipergunakan dalam penelitian ini

2. Kepustakaan, teknik ini digunakan untuk mendapatkan konsep teori dalam penelitian ini.

3. Tes dan pengukuran

Tes dilakukan untuk mengambil data yang peneliti butuhkan untuk mengetahui hubungan koordinasi mata-kaki terhadap kemampuan sepak sila. Adapun tes yang dilakukan di antaranya sebagai berikut :

a Tes koordinasi mata-kaki

b Tes keterampilan sepak sila

Teknik Analisa data Pada penelitian ini peneliti menggunakan analisa statistic korelasi product moment.

\section{HASIL DAN PEMBAHASAN}

Data hasil penelitian kemudian diolah untuk mengetahui seberapa besar hubungan koordinasi mata kaki terhadap keterampilan sepak sila permainan sepak takraw siswa putra kelas VIII SMPN 5 Kota Pekanbaru. Lebih jelasnya peneliti menguraikan sebagai berikut :

Hasil tes koordinasi mata kaki siswa putra kelas VIII SMPN 5 Kota Pekanbaru dilakukan dengan menggunakan Tes koordinasi mata kaki. Setiap siswa dipanggil satu persatu kemudian diukur dan diambil datanya.Hasil pengukuran tes koordinasi mata kaki didapatkan tingkat koordinasi mata kaki siswa putra kelas VIII SMPN 5 Kota Pekanbaru nilai maksimal adalah 12 dan minimal adalah 3.selain data tersebut, peneliti juga menghitung nilai mean, median, modus dan standar deviasi dari data koordinasi mata kaki siswa putra SMPN 5 Kota Pekanbaru. Nilai mean didapat 6.58 nilai median didapat 6 . nilai modus 5, sedangkan standar deviasinya adalah 7.14. Untuk lebih mudah melihat hasil koordinasi mata kaki siswa, perhatikan tabel.1.

Tabel 1. Hasil Koordinasi Mata Kaki

\begin{tabular}{ccc}
\hline $\begin{array}{c}\text { Skor } \\
\text { Koordinasi }\end{array}$ & Jumlah Siswa & Persentase \\
\hline 12 & 1 & $8,33 \%$ \\
\hline 10 & 1 & $8,33 \%$ \\
\hline 9 & 2 & $16,66 \%$ \\
\hline 7 & 2 & $16,66 \%$ \\
\hline 5 & 3 & $25 \%$ \\
\hline 4 & 1 & $8,33 \%$ \\
\hline 3 & 2 & $16,66 \%$ \\
\hline
\end{tabular}

Hasil pengukuran tes sepak sila siswa putra kelas VIII SMPN 5 Kota Pekanbaru didapatkan nilai maksimal adalah 26 dan minimal adalah 10.Frekuensi terbesar terletak pada tiga interval, 18, dan 12 dengan jumlah frekuensi 4 orang. Untuk lebih mudah melihat hasil tes sepak sila siswa, perhatikan tabel. 3 .

Tabel 2. Hasil Perhitungan Keterampilan Sepak Sila 


\begin{tabular}{ccc}
\hline $\begin{array}{c}\text { Skor Tes } \\
\text { Sepak sila }\end{array}$ & Jumlah Siswa & Persentase \\
\hline 26 & 1 & $8,33 \%$ \\
\hline 24 & 1 & $8,33 \%$ \\
\hline 20 & 1 & $8,33 \%$ \\
\hline 18 & 2 & $16,66 \%$ \\
\hline 17 & 1 & $8,33 \%$ \\
\hline 16 & 1 & $8,33 \%$ \\
\hline 14 & 1 & $8,33 \%$ \\
\hline 13 & 1 & $8,33 \%$ \\
\hline 12 & 2 & $16,66 \%$ \\
\hline 10 & 1 & $8,33 \%$ \\
\hline
\end{tabular}

Selain data tersebut, peneliti juga menghitung nilai mean, median, modus dan standar deviasi dari data sepak sila siswa putra SMPN 5 Kota Pekanbaru. Nilai mean didapat 16,66 nilai median didapat 18 . nilai modus 18, sedangkan standar deviasinya adalah 17.32.

lebih jelas dari penjelasan di atas dapat dijelaskan pada tabel ringkasan hasil perhitungan korelasi product moment dan uji t berikut :

Berdasarkan tabel di bawah dapat dijelaskan bahwa besar hubungan koordinasi mata kaki terhadap keterampilan sepak sila adalah sebesar 0.306 artinya hubungan tersebut positif dan berada pada kategori sedang. Guna melihat signifikan hubungan diperoleh nilai $\mathrm{t}$ hitung sebesar 4.77 deangan kaedah penghitung bila $t$ hitung lebih besar dari $\mathrm{t}$ tabel maka hubungan signifikan.

Berdasarkan perhitungan yang telah dilakukan (terlampir) didapatkan nilai $\mathrm{t}$ hitung $=4.77$ nilai $\mathrm{t}$ hitung tersebut kemudian dibandingkan dengan nilai $t$ tabel. Setelah dilihat pada tabel $t$ didapatkan nilai $\mathrm{t}$ tabel pada $\mathrm{dk}=\mathrm{n}-2=12-2=10$ sebesar 2.23.Nilai $\mathrm{t}$ hitung dan $\mathrm{t}$ tabel didapatkan bahwa : $\mathrm{t}$ hitung $>\mathrm{t}$ tabel atau $4.77>2.23$ atau hubungan signifikan.
Langkah selanjutnya adalah melihat seberapa besar hubungan koordinasi mata kaki terhadap keterampilan sepak sila permainan sepak takraw siswa putra smpn 5 kota pekanbaru, menggunakan rumus koofisien determinasi dimana $\mathrm{KD}=\mathrm{r}^{2} \mathrm{x}$ $100 \%$.

Dengan demikian didapatkan $\mathrm{KD}=$ $0.0936 \times 100 \%=9.36 \%$. Artinya koordinasi mata kaki memberikan sumbangan / kontribusi terhadap keterampilan sepak sila dengan persentase sebesar $9.36 \%$.Sedangkan sisanya atau $90.64 \%$ dipengaruhi oleh faktor pendukung lainnya.Faktor pendukung dalam olahraga sepak takraw meliputi pengaruh kekuatan otot tungkai, kelentukan, dan keseimbangan.selain kondisi fisik, keterampilan sepak takraw juga di pengaruhi oleh minat terhadap olahraga sepak takraw dan yang paling penting adalah kedisiplinan dalam berlatih. Kesemuanya membuat kemampuan sepak sila menjadi sempurna.

Tabel 3. Ringkasan Hasil Perhitungan Korelasi Product Moment dan Uji t

\begin{tabular}{ccccc}
\hline $\begin{array}{c}\mathbf{r} \\
\text { hitung }\end{array}$ & t hitung & t tabel & $\mathbf{r}^{2}$ & $\mathbf{r}^{2} \mathbf{x} \mathbf{1 0 0} \%$ \\
\hline 0.306 & 4.77 & 2.23 & $\begin{array}{c}0.093 \\
6\end{array}$ & $9.36 \%$ \\
\hline
\end{tabular}

\section{SIMPULAN}

Berdasarkan penjabaran data penelitian ini, maka peneliti dapat menarik suatu kesimpulan bahwa terdapat hubungan mata kaki terhadap keterampilan sepak sila permainan sepak takraw dengan besarnya $r$ 0,93 (sangat kuat).

Dengan demikian dapat dijelaskan bahwa antara variabel X ( Koordinasi Mata Kaki) dan variabel Y (Keterampilan Sepak sila) terdapat hubungan yang searah diantara 
kedua variabel tersebut. Dengan istilah lain dapat dijelaskan terdapat korelasi positif diantara kedua variabel tersebut. Artinya : pemain sepak takraw yang memiliki koordinasi mata kaki yang baik maka akan dapat memiliki kemampuan sepak sila yang baik pula, demikian sebaliknya. artinya terdapat hubungan atau korelasional antara variabel $\mathrm{X}$ (koordinasi mata kaki) dengan variabel $\mathrm{Y}$ (Keterampilan sepak sila) dengan kategori sedang.

Kesimpulan yang dapat ditarik adalah korelasi positif antara koordinasi mata kaki terhadap keterampilan sepak sila permainan sepak takraw siswa putra kelas VIII SMPN 5 Kota Pekanbaru merupakan Korelasi positif yang meyakinkan.

Artinya Untuk memainkan permainan sepak takraw siswa harus memiliki koordinasi mata kaki yang baik, yang sangat berpengaru terhadap keterampilan dasar sepak takraw terutama sepak sila, dan dari hasil penelitian dan kesimpulan yang telah diuraikan

1. Penelitian ini diharapkan bagi pelatih atau guru pjok sebagai bahan masukan dalam mengevaluasi siswa pasa saat pembeljaran sepak takraw

2. Penelitian ini agar dapat menentukan program latihan yang berkelanjutan guna untuk pencapaian prestasi yang maksimal di kancah regional, nasional, maupun internasional bagipara pemainnya.

3. Dalam bidang ilmu olahraga , dijadikan sebagai sumber pemikiran sebagai penambah cakrawala khususnya ilmu keolahragaan agar lebih luas dalam pengembangannya.

\section{DAFTAR PUSTAKA}

Anggraini, D. (2016). Hubungan Koordinasi
Mata dan Kaki Dengan Kemampuan Passing Pada Permainan Sepak Takraw Siswa SMPN 1 Teluk Kuantan. Jurnal Online Mahasiswa (JOM) Bidang Keguruan Dan Ilmu Pendidikan, 3(2), $1-11$.

Cendra, R., Gazali, N., Parulian, T., Candra, A., \& Apriani, L. (2018). Pelatihan Metode Pengembangan Motorik Kasar Anak Usia Dini Pada Guru PAUD. Jurnal Pengabdian Kepada Masyarakat, 2(1). Retrieved from http://ejurnal.ikippgribojonegoro.ac.id/i ndex.php/J-ABDIPAMAS

Gazali, N. (2016). Kontribusi Kekuatan Otot Lengan Tehadap Kemampuan Servis Atas Atlet Bolavoli. Journal of Physical Education, Sport, Health and Recreations, 3(1), 1-6. Retrieved from http://journal.unnes.ac.id/nju/index.php /jpehs

Herliana, M. N. (2017). Hubungan Peran Kepemimpinan Kepala Sekolah, Iklim Organisasi Sekolah dan Kinerja Guru Dengan Prestasi Belajar Pendidikan Jasmani Olahraga Kesehatan Siswa SMP Negeri Se-Kota Tasikmalaya. Journal Sport Area, 2(2), 44-52.

Nusufi, M. (2014). Korelasi Antara Koordinasi Mata-Kaki dengan Kemampuan Sepak Sila Dalam Permainan Sepak Takraw Atlet Klub Dondong Merah Tahun 2014. Jurnal Handayani, 6(2), 1-8.

Saripin, \& Agust, K. (2017). Hubungan Koordinasi Mata dan Kaki Dengan Keterampilan Sepak Sila Permainan Sepak Takraw Pada Ekstrakurikuler Siswa SMAN 2 Tambang Kabupaten Kampar. Jurnal Online Mahasiswa (JOM) Bidang Keguruan Dan Ilmu Pendidikan, 4(2), 1-10. 
Setiawan, D., Yunitaningrum, W., \& Atiq, A. (2014). Pengaruh Media Bola Plastik Terhadap Teknik Dasar Sepak Sila di Sekolah Menengah Atas. Jurnal Pendidikan Dan Pembelajaran, 4(2), $1-11$.

Sugiyono. (2013). Metode Penelitian Pendidikan. Bandung: Alfabeta.

Suhardi, M., Triansyah, A., \& Haetami, M. (2012). Pengaruh Active Isolated Stretching dan Propioceptive Neuromuscular Facilitation Terhadap Fleksibilitas Tungkai Pada Permainan Sepak Takraw. Jurnal Pendidikan Dan Pembelajaran, 7(9), 1-10.

Sukmana, A. A., \& Allsabah, M. A. H. (2018). Fenomena Kejuaraan Antar Kampung (Tarkam) Sepaktakraw di Kabupaten Blitar. Journal Sport Area, 3(1), 94-101.

Sulaiman. (2004). Sepak Takraw. Semarang: CV. Widya Karya.

Ucup, Y. (2004). Pembelajran Permainan Sepak Takraw: Pendekatan Keterampilan Praktis. Jakarta: Dirjen Olahraga Depdiknas.

Widiastuti. (2011). Tes dan Pengukuran Olahraga. Jakarta: PT. Bumi Timur Jaya. 